This is an author produced version of a paper published in BIOSYSTEMS ENGINEERING. This paper has been peer-reviewed and is proof-corrected, but does not include the journal pagination

Citation for the published paper:

von Wachenfelt, H., Pinzke, S., Nilsson, C., Olsson, O. and Ehlorsson, C.-J. (2009) Force Analysis of Unprovoked Pig Gait on Clean and Fouled Concrete Surfaces. Biosystems Engineering.

Volume: 104 Number: 2, pp 250-257.

http://dx.doi.org/10.1016/j.biosystemseng.2009.06.010

Access to the published version may require journal subscription.

Published with permission from: Elsevier Ltd.

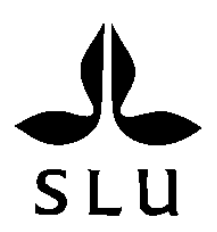

Epsilon Open Archive http://epsilon.slu.se 


\section{Force Analysis of Unprovoked Pig Gait on Clean and Fouled Concrete Surfaces}

von Wachenfelt ${ }^{1}$, H., Pinzke ${ }^{2}$, S., Nilsson ${ }^{1}$, C., Olsson ${ }^{3}$, O., Ehlorsson ${ }^{3}$, C-J.

${ }^{1}$ Dept. of Rural Buildings and Animal Husbandry, Swedish University of Agricultural Science, P. O. Box 86, 23053 Alnarp, Sweden. E-mail corresponding author: Hans.von.Wachenfelt@ltj.slu.se.

${ }^{2}$ Dept. of Work Science, Business Economics and Environmental Psychology, Swedish University of Agricultural Science, P. O. Box 88, 23053 Alnarp, Sweden.

${ }^{3}$ Swedish Animal Health Service, P.O. Box 301 67, SE 10425 Stockholm, Sweden.

\section{Abstract}

Pigs frequently slip and fall on floors, and in some cases they incur injuries. Several studies have shown inadequate floor properties to be the primary cause of most claw disorders in pigs, but to date no clear relationship has been found between claw disorders and floor properties such as friction and surface abrasiveness. To determine this relationship, the factors controlling gait must be characterised.

The present study characterised unprovoked pig gait on clean and fouled concrete floor conditions by the use of kinetics. A force plate was used to record kinetic gait parameters such as stance time, vertical and horizontal forces, and time of peak vertical force.

In a previous study in was shown that pig gait adaption to fouled floor condition resulted in reduced walking speed and prolonged stance phase. In fouled floor condition gait adaptation in the present study showed a greater reduction in horizontal forces than in vertical forces, which reduced the peak utilised coefficient of friction (UCOF) and delayed the application of full vertical forces by the fore limbs.

Keywords: floor, pig, concrete, friction, gait, force plate, kinetics.

\section{Introduction}

Pigs frequently suffer slips and falls on floors and in some cases they incur injuries. Inadequate floor properties are considered to be the primary cause of the majority of claw disorders (Gjein 1994; Jörgensen et al., 2003; Lahrmann et al., 2003). Floor properties such as surface friction, abrasiveness and softness were technically characterised by Webb \& Nilsson (1983) and Nilsson (1988). In order to understand the relationship floor properties and claw disorders, these characterisations have to be supplemented by studies of animal reactions in terms of behaviour, health and performance. So far little work has been published where the interaction between floor and animal has been studied in order to assess lameness and floor properties (Albutt et al., 1990; Thorup et al., 2007). Within the European Union (EFSA, 2005), currently no mandatory testing and approval schemes for floors and flooring systems use animal wellbeing as the indicator.

In order to minimise slip and fall injuries in pigs, it is important to understand gait biomechanics (Applegate et al., 1988; Cham \& Redfern, 2002) and to understand the factors that cause the slip and fall accidents and their interactions with environmental factors (Perkins 1978; Strandberg \& Lanshammar, 1981; Redfern \& DiPasquale, 1997; Hanson et al., 1999). Gait biomechanics and the state of the pig sensory and neuromuscular system are included in 
animal factors. Among the most important environmental factors are floor properties (Bring, 1964; Kovacs \& Beer, 1979; Strandberg \& Lanshammar, 1981; Webb \& Clark, 1981a, b; Nilsson, 1988; Pedersen et al., 2005) and their interactions with the pig claw (Webb \& Nilsson, 1983; Webb, 1984; Applegate et al., 1988; McKee et al., 1995; Thorup et al., 2007).

Frictional properties are mainly described by the coefficient of friction (COF). The COF determines the horizontal (frictional) force that can be generated between the contact surfaces of two objects in relation to the vertical force between these objects (Hall, 1995; Chang et al., 2001). The amplitude of the frictional force depends on the character of the mechanical and molecular interactions between the two surfaces in contact.

On horizontal surfaces the COF is determined by the ratio of the horizontal and vertical forces, which is referred to as the static COF (SCOF) just before and when objects start to slide relative to each other, and dynamic COF (DCOF) during sliding. During sliding, the magnitude of the dynamic COF value remains constant and is theoretically lower than the SCOF (Hall, 1995).

The forces exerted on the ground by a pig claw during walking are counteracted by an opposing force of the same magnitude, the ground reaction force (GRF). The resolved forces of GRF in vertical, longitudinal and transverse components can be measured by a force plate. Whether or not the claw slips is determined by the ratio of the horizontal force to the vertical or normal force, termed the utilised coefficient of friction (UCOF) (Fig. 1). Slip occurs when $\mathrm{UCOF}>\mathrm{COF}$.

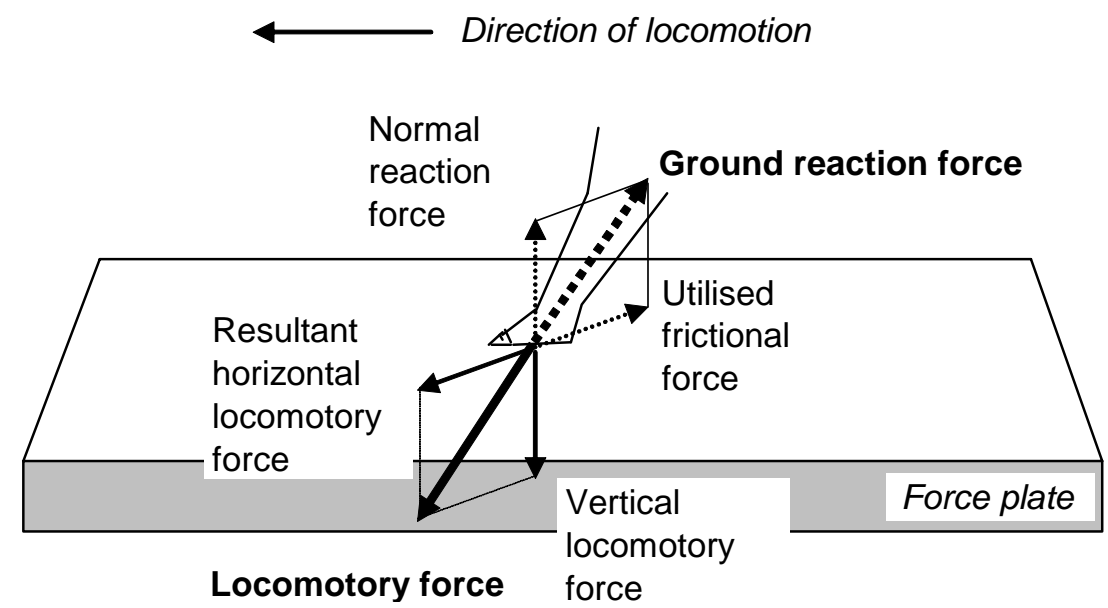

Fig. 1. The locomotory force and corresponding ground reaction force (GRF) components at claw in the initial part of stance phase of a walking pig.

In pig gait, the COF depends on claw properties, flooring and the contact surface interface (floor condition). Floor conditions (dry, wet or manure-fouled) affect the COF value. Typical COF values for cows range from 0.25 to 0.55 depending on floor conditions and testing method (Webb \& Nilsson, 1983; Phillips \& Morris, 2001). A sufficient COF value for standing and locomotion is suggested to be at least 0.35-0.40 (Webb \& Nilsson, 1983).

Cham \& Redfern (2002) found that a human subject used both postural and temporal gait adaptions to reduce the risk of slipping when anticipating slippery floor conditions, while according to Powers et al. (2002), the peak UCOF increases with increasing walking speed. In order to understand the relationship between floor properties and claw disorders in cows, slip direction and magnitude (Albutt et al., 1990), gait pattern on dry and slurry-covered floors 
(Phillips \& Morris, 2000; Telezhenko \& Bergsten, 2005), and how UCOF values differ during different locomotion situations (van der Tol et al., 2005) have been investigated.

Animal gait assessments by means of kinematics/kinetics were carried out by (Hottinger et al., 1996; Barrey, 1999; Hodson et al., 2001). The same methods were used by Thorup et al. (2007) for assessing a relationship between pig gait and floor properties. Recent studies in cows assessed relationships between lameness and gait (Flower et al., 2005) and between gait, lameness and floor properties (Flower et al., 2007). In the present study, an unprovoked pig (equivalent to the unrestrained cow in van der Tol et al., 2005) is defined as a pig that is not subjected to any environmental provocation that could disturb its gait.

De Belie (1997) found complaints from $40 \%$ of farmers concerning surface degradation of concrete slats within 5 years of use, and the complaints focused specifically on increased surface roughness, enlarged gaps between slats and animal injuries. Slatted concrete floors should be investigated, but it is essential to obtain information on unprovoked pig gait on solid concrete floors as a reference before pig gait on slatted concrete floors is characterised.

The aim of the present study was to characterise unprovoked pig gait on concrete with different surface conditions by the use of kinetics.

\section{Materials and Methods}

\subsection{Animals}

Ten Swedish Landrace pigs, 3 barrows and 7 gilts, were used during the test period ( $3 \mathrm{~d})$. The pigs (mean body weight $113 \mathrm{~kg}, \mathrm{SD}=8 \mathrm{~kg}$ ) were chosen from a farm where the pens had straw-covered solid concrete floors and were fed at moderate intensity, in order to obtain pigs with good claw health. Before and after the trial the claws were examined according to a standard procedure (Brooks et al., 1977) by a veterinary surgeon who also subjectively judged the pigs to have healthy claws and gait. The pigs were fed $3.0 \mathrm{~kg}$ per pig and day according to the feeding norms in Sweden.

\subsection{Experimental set-up}

The test area consisted of two rectangular pens with a test aisle in between. A return aisle made it possible to walk the pigs back to the starting point. The pen areas had solid concrete flooring, while the test aisle were covered by replaceable slabs. Pig gait on the test aisle was recorded by an built-in force plate (FP) level with the paved surface and a perpendicularly placed digital video (DV) camera (Fig. 2). Kinematic results from the locomotion study were reported in von Wachenfelt et al. (2008). Temperature and humidity were recorded by a data logger and the indoor temperature was $13 \pm 5^{\circ} \mathrm{C}$ and the humidity $66 \pm 15 \%$ during the test period.

The start of pig walking was communicated to the holding pen personnel visually and FP data were collected during the passage of the moving pigs at $1 \mathrm{kHz}$. The test aisle and the FP were covered with the same concrete flooring material. The GRF data acquisition system consisted of an FP, connected to a digital converter and a computer. Three GRFs, vertical and horizontal components (transverse and lateral), were recorded by the FP. A measuring programme (LabView 8.0, USA) was used for controlling measuring instruments regarding sampling rate, data storage and correction for material height over the FP cover.

A calibration of the FP was carried out before and after the experiment, together with a temperature sensitivity test. An accuracy determination was made by calculating the maximum error for COF according to Holman (2001), and the results fell within the FP specifications. To avoid error caused by temperature sensitivity, the FP was zero-set once per hour. 


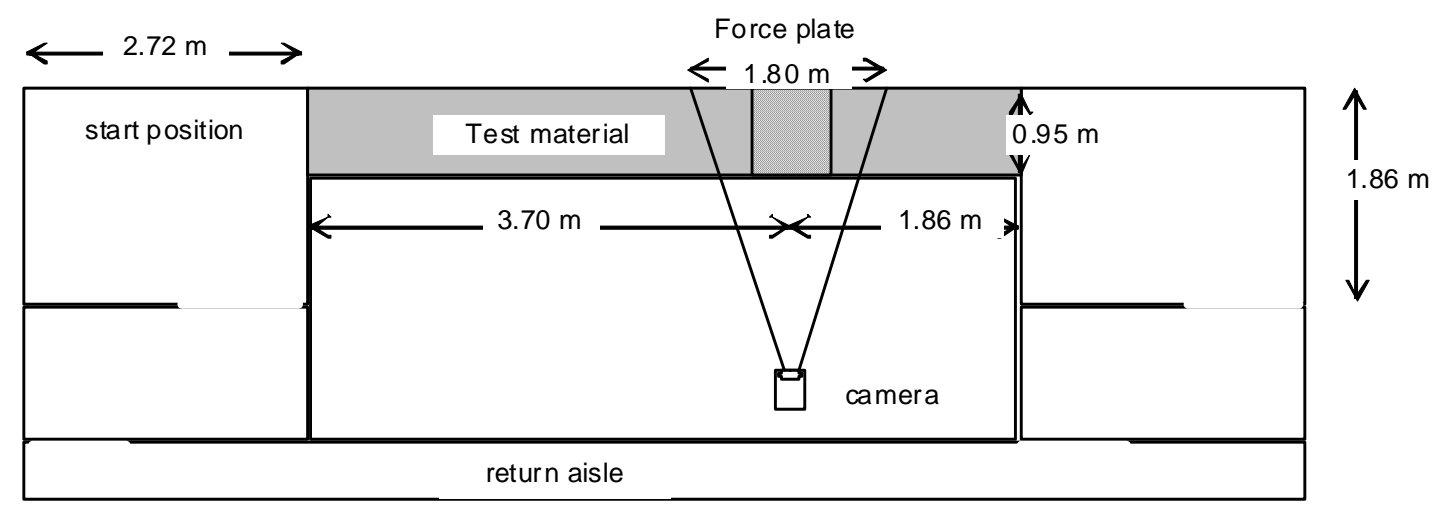

Fig. 2. Plan of test area.

\subsection{Floor conditions}

Two concrete surface conditions were tested; one clean and one fouled by pig faeces. For more details, see von Wachenfelt et al. (2008).

\subsection{Experiment}

The number of passages was 10 for each pig per replica and two replicas were conducted for each floor condition. The pigs were randomly selected for each passage and in general, only data from the last 6 passages were used, as this gave the pigs time to become accustomed to the surface conditions before sampling. A successful passage by an unprovoked pig was defined as a pig walking at a steady pace without stopping or jumping; placing its front or rear claws or both claws, but separated in time, entirely on the force plate. In some passages more than one fore and hind limb was fully registered. In clean condition $4 \%$ of the passages were discarded and replaced by a new passage, but in fouled conditions this rose to $12 \%$. The average time to complete the 10 passages was 5 minutes per pig.

\subsection{Data processing}

Stance time (the time when claw had physical contact with the floor), mean and peak values for vertical and horizontal forces, and time of peak vertical force were calculated from the GRF data. All GRF data were normalised to pig body weight. A data set was obtained by sampling the GRF data in 300 evenly distributed values (corresponding to mean stance phase length) during the stance phase. The sampling was performed in three force directions using the vertical force curve as a template. The samples were compiled as a mean value for each of the 300 sampling points per pig and floor condition. From the 300 mean values per pig and floor condition mean and peak force parameters were calculated for 10 pigs per floor condition.

The claw force data were processed to determine the ratio of horizontal to normal forces (UCOF). The UCOF data were screened for spurious values and values less than $10 \%$ of the peak vertical force were discarded. These originated from small vertical force values during claw-on and claw-off. Because of division by small numbers in the UCOF ratio, these UCOF values showed false maxima (Cham \& Redfern, 2002; Powers et al., 2002).

\subsection{Statistics}

A paired t-test was used for FP data to compare differences between surface conditions and differences between front and rear claws within the same type of surface conditions. The data were tested for normal distribution. The probability limits for evaluating statistical significance were: $*=\mathrm{p}<0.05 ; * *=\mathrm{p}<0.01 ; * * *=\mathrm{p}<0.001$. 


\subsection{Coefficient of friction}

Prior to the tests, floor friction assessments were made by two different test devices, a horizontal pull slip meter (PSM) designed at the Department of Rural Buildings, Swedish University of Agricultural Science, and a skid resistance tester (SRT) of dynamic pendulum impact-type (ASTM, 1993). According to a Shore testing meter, the pig claw heel bulbs had a hardness of $30-35^{\circ}$ Shore A. To reflect the conditions at the claw and floor interface during actual slip (Chang et al., 2001), the test body of both the pendulum slider and the horizontal pull slip meter were covered by a piece of leather corresponding to pig claw hardness and friction (Bring, 1964). The leather used was standard commercial leather (ISS, 2003).

The contact area of the sliding body of the PSM corresponded to a claw area of $0.002 \mathrm{~m}^{2}$ in accordance with Baxter (1984) and a pig weight of $61 \mathrm{~kg}$, which also generated the normal load. The test body was pulled horizontally along the floor by a hydraulic piston and the force required to pull it was recorded by a load cell placed between the test body and the piston. The ratio between the pulling force and total vertical (normal) force was calculated as the peak SCOF, occurring at the moment the body was set in motion, and as DCOF, the mean during a distance of $0.15 \mathrm{~m}$. A mean of 10 runs was calculated on different locations for each type of floor conditions for SCOF and DCOF.

The SRT measures the energy loss when a rubber slider edge, positioned at the end of a pendulum, is propelled over the test surface. The values obtained, a British Pendulum Number (BPN), represent the frictional properties. The greater the friction, the more the swing is retarded, and the larger the BPN reading. Immediately after each pig trial, five swings of the pendulum were made at three random locations on the FP concrete surface according to ASTM (1993). The BPN was expressed as the mean of the 15 values obtained. For comparison, the SRT was also run over the surface conditions tested with its original rubber test body.

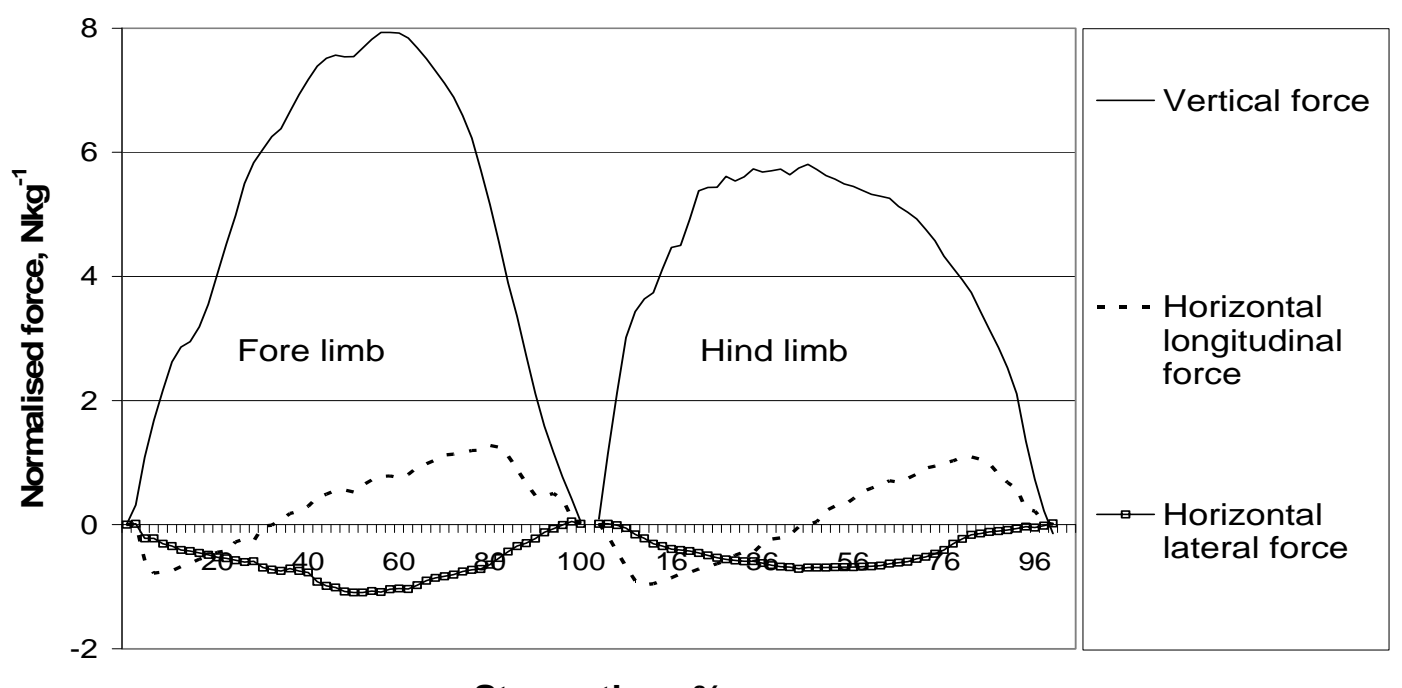

Stance time, \%

Fig.3. Normalised GRF exerted from fore and hind limbs during stance phase from 10 pigs. Values derived from force plate measurements on clean concrete.

\section{Results}

Mean vertical and horizontal force curves exerted by fore and hind limbs on the force plate from 10 pigs are illustrated in Fig. 3. The vertical force of both limbs has a lower and a higher peak. The longitudinal horizontal force roughly described a sinusoidal curve, with a negative maximum illustrating backward forces acting on the claw followed by a positive maximum with forward forces acting on the claw. The lateral horizontal force was less consistent and 
varied between fore and hind limbs, but was mainly negative during the stance phase, which meant that the claw had an outward thrust in the lateral direction.

\subsection{Gait difference between fore and hind limbs}

For both types of surface conditions, the applied mean vertical force and the peak vertical force from fore limbs were higher than the force exerted by hind limbs (Table 1). The time of peak vertical force occurred later for fore limbs compared with hind limbs in both types of floor conditions.

Table 1. Effects of floor conditions on claw and gait parameters, $n=160$ for fore limb (F) and n=140 for hind limb $(\mathrm{H})$

\begin{tabular}{|c|c|c|c|c|c|c|}
\hline \multirow[t]{2}{*}{ Parameter $^{1}$} & \multirow[t]{2}{*}{$\mathrm{Claw}^{2}$} & \multicolumn{5}{|c|}{ Floor conditions } \\
\hline & & $\begin{array}{l}\text { Clean } \\
\text { Mean (SD) }\end{array}$ & $p^{3}$ & $\begin{array}{l}\text { Fouled } \\
\text { Mean (SD) }\end{array}$ & $p^{3}$ & $p^{4}$ \\
\hline \multirow[t]{2}{*}{ Mean vertical force, $\mathrm{Nkg}^{-1}$} & $\mathrm{~F}$ & $5.51(0.33)$ & $* * *$ & $5.12(0.46)$ & $* * *$ & $* *$ \\
\hline & $\mathrm{H}$ & $4.24(0.40)$ & & $4.19(0.38)$ & & ns \\
\hline \multirow[t]{2}{*}{ Peak vertical force, $\mathrm{Nkg}^{-1}$} & $\mathrm{~F}$ & $8.44(0.68)$ & $* * *$ & $7.29(0.82)$ & $* * *$ & $* * *$ \\
\hline & $\mathrm{H}$ & $6.06(0.63)$ & & $5.61(0.64)$ & & $*$ \\
\hline \multirow[t]{2}{*}{ Timing of peak vertical force, $s$} & $\mathrm{~F}$ & $0.15(0.02)$ & $* *$ & $0.20(0.04)$ & $* * *$ & $* *$ \\
\hline & $\mathrm{H}$ & $0.13(0.02)$ & & $0.15(0.03)$ & & ns \\
\hline \multirow[t]{2}{*}{ Peak longitudinal horizontal force, $\mathrm{Nkg}^{-1}$} & $\mathrm{~F}$ & $0.36(0.23)$ & $* * *$ & $0.31(0.20)$ & $* *$ & ns \\
\hline & $\mathrm{H}$ & $0.67(0.22)$ & & $0.55(0.22)$ & & * \\
\hline \multirow[t]{2}{*}{ Min longitudinal horizontal force, $\mathrm{Nkg}^{-1}$} & $\mathrm{~F}$ & $-1.25(0.16)$ & $* * *$ & $-0.68(0.17)$ & ns & $* * *$ \\
\hline & $\mathrm{H}$ & $-0.81(0.19)$ & & $-0.53(0.16)$ & & $* * *$ \\
\hline \multirow[t]{2}{*}{ Peak lateral horizontal force, $\mathrm{Nkg}^{-1}$} & $\mathrm{~F}$ & $0.09(0.05)$ & ns & $0.07(0.05)$ & ns & ns \\
\hline & $\mathrm{H}$ & $0.12(0.14)$ & & $0.05(0.05)$ & & ns \\
\hline \multirow[t]{2}{*}{ Min lateral horizontal force, $\mathrm{Nkg}^{-1}$} & $\mathrm{~F}$ & $-0.50(0.22)$ & * & $-0.21(0.09)$ & ns & $* * *$ \\
\hline & $\mathrm{H}$ & $-0.24(0.16)$ & & $-0.20(0.12)$ & & ns \\
\hline \multirow[t]{2}{*}{ Peak UCOF } & $\mathrm{F}$ & $0.54(0.06)$ & ns & $0.43(0.04)$ & ns & $* * *$ \\
\hline & $\mathrm{H}$ & $0.51(0.04)$ & & $0.40(0.04)$ & & $* * *$ \\
\hline
\end{tabular}

\footnotetext{
${ }^{1)}$ Normalised to body weight

${ }^{2)} \mathrm{F}$ = fore limb, $\mathrm{H}=$ hind limb

3) Significance level comparing fore and hind limbs

4) Significance level comparing surface conditions
}

The peak longitudinal horizontal force was lower for fore limbs than for hind limbs in both types of floor conditions, but no difference was found for the peak lateral horizontal force. Minimum longitudinal and minimum lateral horizontal forces applied by fore limbs were only lower than for hind limbs on clean concrete. As regards peak UCOF, there was no difference between fore and hind limbs in any type of floor conditions.

\subsection{Gait differences due to floor conditions}

The peak vertical force applied was higher and the time of peak vertical force occurred earlier for fore limbs on clean floors than on fouled (Table 1). The minimum longitudinal force applied in fouled floor conditions decreased for both fore and hind limbs compared with clean floor conditions. For the minimum lateral horizontal force, the decrease on fouled floors was only significant for fore limbs. Neither peak longitudinal nor peak lateral horizontal force showed any significant reduction between clean and fouled floor conditions, with the exception of peak longitudinal horizontal force for hind limbs. 


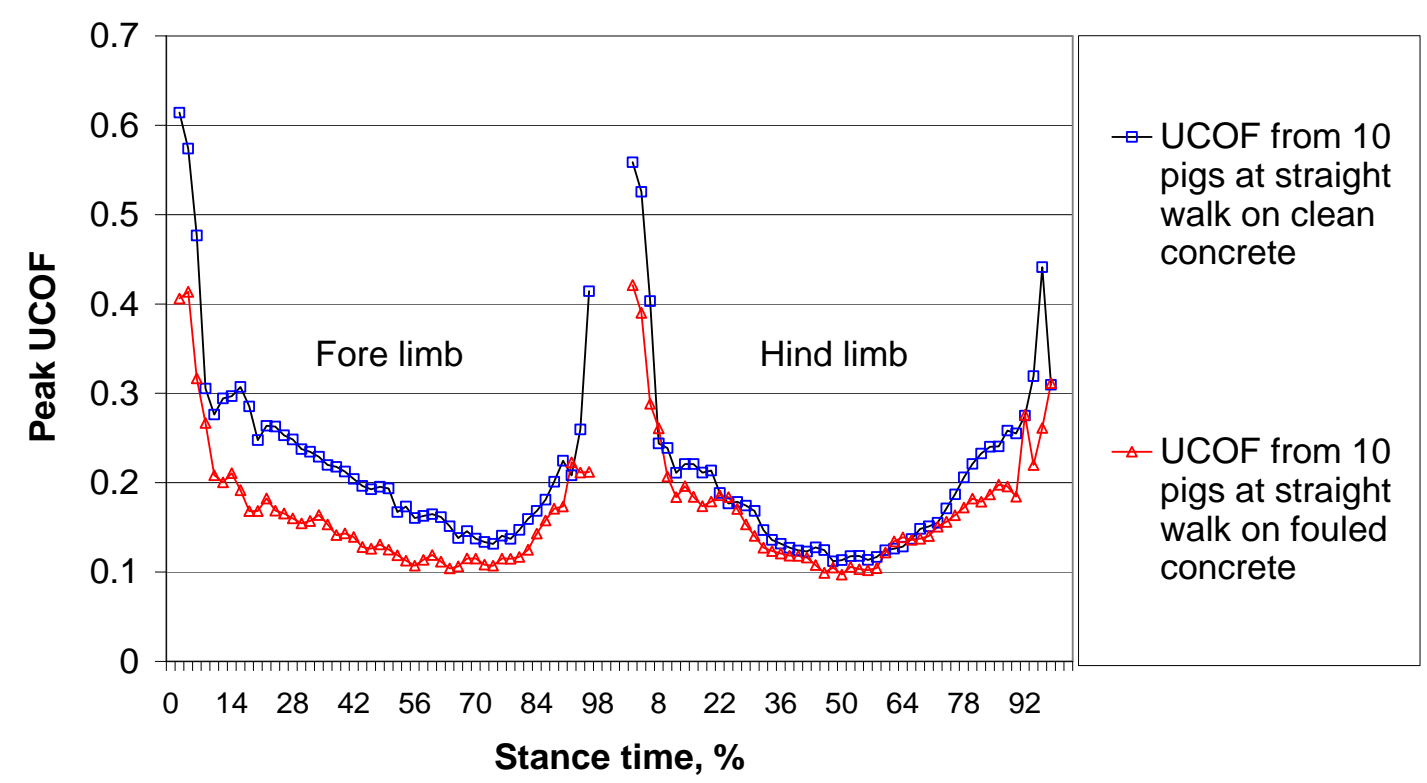

Fig.4. Peak UCOF data during stance phase for 10 pigs, a) fore claws, b) hind claws, walking on clean and fouled concrete respectively. Values at the very start and end of the stance phase were discarded to avoid 'instability' regions when both shear and normal forces approach zero.

The highest UCOF occurred at claw-on and at claw-off, with a minimum at the mid-stance phase for both fore and hind limbs in both types of floor conditions (Fig. 4). Peak UCOF of both fore and hind limbs decreased in fouled floor conditions compared with clean.

\subsection{Floor friction}

With the PSM testing device, both SCOF and DCOF were significantly higher in clean than fouled floor condition (Table 2). Corresponding difference were also found for SRT leather and SRT rubber.

Table 2. The coefficients of static friction (SCOF), dynamic friction (DCOF) and skid resistance (BPN) for the floorings tested both in laboratory and pig house experiment (PSM: $\mathrm{n}=10$, SRT: $\mathrm{n}=15$ )

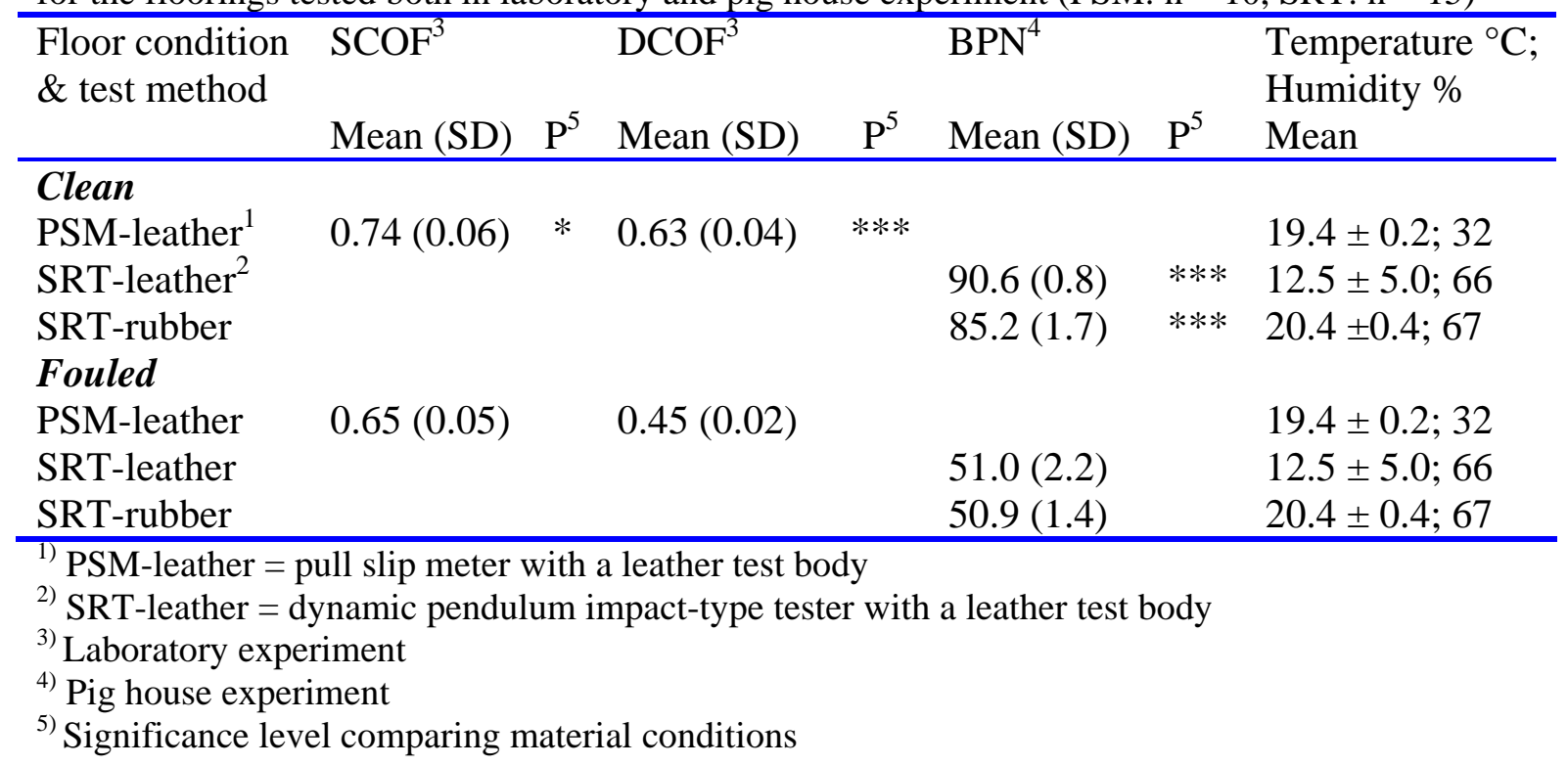




\section{Discussion}

The results of this study confirmed that pigs adapted their gait to the floor conditions. In a previous study the gait adaption resulted in a significant reduction in walking speed (1.65 to $1.31 \mathrm{~ms}^{-1}$ ) and a prolonged stance phase (von Wachenfelt et al., 2008). In the present study this adaption resulted in a reduction in peak UCOF on fouled floors, thus reducing the possible risk of slip and fall (Strandberg \& Lanshammar, 1981; Buczek \& Banks, 1996; Hanson et al., 1999). The UCOF reduction took the form of a higher reduction in horizontal forces compared with vertical forces.

A major difference was observed between fore and hind limbs, with higher peak vertical forces and mean vertical forces for the fore limbs compared with the hind. Both fore and hind limbs, but especially fore limbs, used a delayed application of full vertical force in fouled floor conditions compared with clean.

For humans, the force reduction in slippery floor conditions is obtained by temporal and kinematic gait adaptation (Cham \& Redfern, 2002). Gait analysis of walking pigs showed a lower walking speed (20\%), a shorter stride length (16\%) and an increased stance time on fouled concrete surfaces compared with clean surfaces for both fore and hind claws (von Wachenfelt et al., 2008). This is similar to the results with cows, Jungbluth et al. (2003) and Telezhenko \& Bergsten (2005) showed that cows reduce their walking speed and stride length on surfaces with lower friction, while Phillips \& Morris (2000) reported that cows walk more slowly on contaminated surfaces than on dry. Thorup et al. (2007) demonstrated that walking pigs (74 kg) reduced their speed (by 16\%), stride length (by 7\%) and prolonged their stance phase (by 15\%) on a greasy concrete surface compared with a dry.

The mean vertical force values obtained in the present study revealed that the pigs had an uneven weight distribution during locomotion, with $56 \%$ of the body weight being carried by the fore limbs. This uneven weight distribution has also been found in cows (Webb \& Clark, 1981a) and $74 \mathrm{~kg}$ pigs (Thorup et al., 2007). Applegate et al. (1988) reported that fore limbs are more affected by surface conditions than hind limbs, and argued that fore limbs at toe-on lie further from the body's centre of gravity than hind, which would expose the fore limbs to greater horizontal forces, resulting in more slips for fore limbs. Accordingly, leg problems associated with high vertical loads and slips are therefore more likely to arise in fore limbs than in hind limbs.

The peak vertical force of pigs walking at $1.6 \mathrm{~m} / \mathrm{s}$ generated a weight distribution of $57 \%$ on the fore claws (Table 1). Comparable peak loads have been found in 20-35 kg dogs (Jayes \& Alexander, 1978; Tano et al., 1998) at walking speeds of approximately $1 \mathrm{~ms}^{-1}$, but are lower in $630 \mathrm{~kg}$ cows (van der Tol et al., 2005), probably due to differences in walking speed.

The delayed application of full vertical force, illustrated by the timing of peak vertical force, showed a clear adaption, especially for fore limbs in fouled floor conditions. This suggests that fore and hind limbs have different tasks in locomoting the body.

Longitudinal horizontal forces express the sequence of braking and propulsion of both fore and hind limbs during stance phase. The major component of braking takes place in the first part of the stance phase, while the propulsion takes place in the latter part. The forces occurring shortly after claw contact are considered to play an important role in slips and falls (Redfern et al., 2001). Small peaks in GRF were recorded at claw-on, about $0.04 \mathrm{~s}$ after claw contact with the floor. According to Jayes \& Alexander (1978), Perkins (1978) and Whittle (1999), these forces are a result of the forward movement of the claw as it makes contact with the floor.

In adapting to the fouled floor conditions, the pigs reduced the braking force by $45 \%$ and $35 \%$ for fore and hind limbs respectively (Table 1). In clean floor conditions the pigs utilised 
45\% more braking force from the fore limbs compared with the hind, whereas in fouled floor conditions the difference in braking force between fore and hind limbs dropped to approximately $20 \%$.

In contrast to the present study Thorup et al. (2007) showed that the braking force on dry flooring was greatest in hind limbs, which probably was a result of less pig body weight and walking speed, whereas in fouled floor conditions the braking force was divided equally between the fore and hind limbs in agreement with the present study.

Thorup et al. (2007) found the propulsion force to be divided equally between the limbs in dry floor conditions but decreased on the fore limbs, and thus shifted propulsion to the hind limbs, in contaminated floor conditions. In the present study the propulsion force from the hind limbs was almost twice as large as that from the fore limbs in both clean and fouled floor conditions, probably as a result of higher walking speed and body weight, while on fouled floors the propulsion force was lowered by approx. 15\% for both limbs, in agreement with Thorup et al. (2007).

The lateral horizontal forces exerted express the stabilisation effort needed to maintain the travelling direction of the moving body. The outward correction force in clean floor conditions was larger for fore limbs than for hind and resulted in a $60 \%$ reduction for fore limbs on fouled floors compared with clean. The reduced correction, not significantly inward, indicates that in fouled floor conditions pigs choose to restrict the lateral stabilising forces in order to gain stability, which confirm the results of Thorup et al. (2007). The two- to three-fold higher inward correction observed in their study for the hind limbs compared with the fore, especially in dry floor conditions, was not found in the present study.

The peak UCOF reduction in fouled floor conditions showed a pig gait adaptation to fouled conditions similar to that reported by Thorup et al. (2007). In clean floor conditions pigs exerted high peak UCOF, revealing a confident walking gait. The magnitude of the UCOF reduction (20\%) and the UCOF values obtained in dry surface conditions (0.54) were somewhat higher than those reported by Thorup et al. (2007). These differences can be attributed to heavier pigs, higher walking speed and different floor surface conditions (Burnfield \& Powers, 2003). The lower walking speed on fouled flooring contributed to the reduction in UCOF values, as also reported by Cham \& Redfern (2002) and Powers et al. (2002).

The comparable peak UCOF value obtained in tests on humans in dry floor conditions is about 0.20 (McVay \& Redfern, 1994; Burnfield et al., 2005). For cows on dry floors and level straight walking, the UCOF value is reported to be 0.54 , while it is 0.83 for cows walking along a curved alley (van der Tol et al., 2005).

Compared with slip resistance values for animal housing floors in general (Richter, 2002), the SRT values obtained for the clean floor in the present study were rated 'very good to excessively rough' (70-80 BPN), which suggests that no slips occurred during clean floor conditions.

The mean body weight of the pigs in the present study remained the same during the test period, as the test was completed within 3 successive days, which means that differences in gait were not caused by differences in body size. All animals were found to have healthy claws and gait, which means that pig walking in the test aisle reflected normal pig gait on clean and fouled concrete surfaces. The walking conditions were far less demanding for the pigs in the study compared with ordinary pen conditions, in the sense that only one pig at a time walked the test aisle at a self-chosen speed under no restrictions. Pen situations can often involve competition between pigs in relatively small areas, where the floors could be wet and fouled, or sometimes 
degraded through age and food residues (De Belie, 1997), which stresses the importance of the floor properties and their interaction with animal feet (Webb \& Nilsson, 1983).

The accuracy of a force plate analysis is largly determined by the walking speed of the subject. McLaughlin et al. (1996) concluded that variation in subject velocity should be minimised in performing force plate analysis in horses. In dogs, the recommended variation should be less than $0.6 \mathrm{~ms}^{-1}$ at the walk (Roush \& McLaughlin, 1994; Tano et al., 1998).

In laboratory measurements on humans, self-chosen gait speeds have ranged from 0.97 to $1.51 \mathrm{~ms}^{-1}$ (Redfern et al., 2001). In the present study the mean difference in walking speed was $0.5 \mathrm{~ms}^{-1}$ between floor conditions. The dynamic noise level was 2, 8 and $10 \%$ for vertical, longitudinal and lateral forces respectively. The standard deviation of GRF forces were somewhat higher but of same order compared to corresponding studies (Hodson et al., 2001; van der Tol et al., 2005; Thorup et al., 2007).

\section{Conclusions}

In clean floor conditions pigs exerted a high peak UCOF, revealing a confident walking gait, as well as higher peak and mean vertical forces for the fore limbs compared with the hind limbs. On clean floors, pigs had an uneven weight distribution of $56 \%$ on the fore limbs, utilised $45 \%$ more braking force from the fore limbs compared with the hind limbs and had a propulsion force almost twice as large from the hind limbs as from the fore limbs.

In our previous study (von Wachenfelt et al., 2008) pig adaption to fouled floor conditions resulted in reduced walking speed and prolonged stance phase. To avoid the risk of slips and falls, pigs in the present study altered their gait in accordance with floor conditions by a higher reduction of horizontal forces compared with vertical forces in order to reduce peak UCOF. Pigs also altered their gait by delayed application of full vertical force by the fore limbs in fouled floor conditions.

To obtain more precise design citeria for floors in pig houses it is important to conduct further research where actual slips occur and relate the biomechanics to slip resistance measurements. Such studies should include analysis of friction and the number of slip incidents on different floor types.

\section{Acknowledgements}

The authors gratefully acknowledge financial support from the Swedish Research Council for Environment, Agricultural Sciences and Spatial Planning (FORMAS) for the research work reported in this paper, and special funding from the Crafoord Foundation for digital video equipment.

\section{References}

Albutt, R W, Dumelow, J, Cermak, JP, Owen, JE (1990). Slip resistance of solid concrete floors in cattle buildings. Journal of Agricultural Engineering Research, 45, 137-147.

Applegate, A L, Curtis, S E, Groppel, J L, McFarlane, J M, Widowski, T M (1988). Footing and gait of pigs on different concrete surfaces. Journal of Animal Science, 66(2), 334-341.

ASTM (1993). Standard test method for measuring surface frictional properties using the British pendulum tester. ASTM E303-93.

Barrey, E (1999). Methods, Applications and Limitations of Gait Analysis in Horses. The Veterinary Journal, 157, 7-22.

Baxter, S H (1984). Intensive pig production: Environmental Management and design. New York, Granada, USA.

Bring, C (1964). Friktion och halkning (Friction and slipping). The National Swedish Council for Building Research, Sweden. Rapport 112, p. 152. 
Brooks, P H, Smith, D A, Irwin, V C R (1977). Biotin-supplementation of diets; the incidence of foot lesions, and the reproductive performance of sows. Veterinary Record, 101, 46-50.

Buczek, F, L, Banks, S A (1996). High-resolution force plate analysis of utilized slip resistance in human walking. Journal of Testing and Evaluation, 24(6), 353-358.

Burnfield, J M, Powers C M (2003). Influence of age and gender of utilized coefficient of friction during walking at different speeds. Metrology of pedestrian locomotion and slip resistance, ASTM STP 1424. M. I. Marpet, Sapienza, M.A. West Conshohocken, ASTM International, 2003, 3-16.

Burnfield, J M, Tsai, Y J, Powers C M (2005). Comparison of utilized coefficient of friction during different walking tasks in persons with and without a disability. Gait and Posture, (22), 82-88.

Cham, R, Redfern, M S (2002). Changes in gait when anticipating slippery floors. Gait and Posture, 15, 159-171.

Chang, W R, Gronqvist, R, Leclercq, S, Myung, R, Makkonen, L, Strandberg, L, Brungraber, R J, Mattke, U, Thorpe, S C (2001). The role of friction in the measurement of slipperiness, Part 1: Friction mechanisms and definition of test conditions. Ergonomics, 44(13), 12171232.

De Belie, N (1997). A survey on concrete floors in pig houses and their degradation. Journal of Agricultural Engineering Research, 66, 151-156.

EFSA (2005). The welfare of weaners and rearing pigs: effect of different space allowences and floor types. EFSA-Q-2004-077. EFSA Journal, 268, 1-19.

Flower, F C, de Passillé, A M, Weary, D M, Sanderson, D J, Ruschen, J (2007). Softer, higherfriction flooring improves gait of cows with and without ulcers. Journal of Dairy Science, 90, 1235-1242.

Flower, F C, Sanderson, D J, Weary, D M (2005). Hoof pathologies influence kinematic measures of dairy cow gait. Journal of Dairy Science, 88, 3166-3173.

Gjein, H (1994). Housing of pregnant sows - a field study on health and welfare, with special emphasis on claw lesions. Dr Sci Thesis. Oslo, Norwegian College of Veterinary Medicine, Norway.

Hall, S J (1995). Basic Biomechanics, WCB/McGraw-Hill New York, NY, USA. pp 366.

Hanson, J P, Redfern, M S, Mazumdar, M (1999). Predicting slips and falls considering required and available friction. Ergonomics, 42(12), 1619-1633.

Hodson, E, Clayton, H M, Lanovaz, J L (2001). The hindlimb in walking horses: 1. Kinematics and ground reaction forces. Equine Veterinary Journal, 33, 38-43.

Holman, J F (2001). Experimental methods for engineers. New York, McGraw Hill, USA.

Hottinger, H A, DeCamp, C E, Olivier, N B, Hauptman, J G, Soutas-Little, RW (1996). Noninvasive kinematic analysis of the walk in healthy large-breed dogs. American Journal of Veterinary Research, 57, 381-388.

ISS (2003). Swedish Standard; Leather - physical and mechanical tests - determination of tensile strength and percentage extension (SS-EN ISO 3376); Leather - physical and mechanical tests - determination of softness (SS-EN ISO 17235). Swedish Standards Institute, 11880 Stockholm, Sweden.

Jayes, A S, Alexander, R McN (1978). Mechanics of locomotion of dogs (Canis familiaris) and sheep (Ovis aries). Journal of Zoology, London, 185, 289-309.

Jungbluth, T, Bentz, B, Wandel, H (2003). Soft walking areas in loose housing systems for dairy cows. Fifth International Dairy Housing Proceedings of the 29-31 January 2003 Conference, Fort Worth, Texas, USA, ASAE Publication Number 701P0203.

Jørgensen, B (2003). Influence of floor type and stocking density on leg weakness, osteochondrosis and claw disorders in slaughter pigs. Animal Science (UK). 77. 439-449. 
Kovacs, A B, Beer, G Y (1979). The mechanical properties and qualities of floors for pigs in relation to limb disorders. The Pig Veterinary Society Proceedings 5, 99-104.

Lahrmann, K H, Steinberg, C, Dahms, S, Heller, P (2003). Prevalences of herd specific factors and limb disorders, and their associations in intensive swine production. Berliner und Munchener Tierarztliche Wochenschrift, 116 (1-2), 67-73.

McKee, C I, Dumelow, J (1995). A Review of the Factors Involved in Developing Effective Non-Slip Floors for Pigs. Journal of Agricultural Engineering Research, 60(1), 35-42.

McLaughlin, R M J, Gaughan, E M, Roush, J K, Skaggs, C L (1996). Effects of subject velocity on ground reaction force measurements and stance times in clinically normal horses at the walk and trot. American Journal of Veterinary Research, 57(1), 7-11.

McVay, E J, Redfern, M S (1994). Rampway safety: foot forces as a function of rampway angle. American Industrial Hygiene Association Journal, (55), 626-634.

Nilsson, C. (1988). Floors in Animal Houses - Technical Design with Respect to the Biological Needs of Animals in Reference to the Thermal, Friction and Abrasive Characteristics and the Softness of the Flooring Material. Dr Science Thesis. Repport 61. Swedish University of Agricultural Sciences, Department of Farm Buildings, Division of Agricultural Building Technology. Lund, Sweden.

Pedersen, S (2005). Friction and shock absorbtion for floors in pig pens. Concrete for sustainable agriculture; agro-, aqua-, and community applications, San Lorenzo de El Escorial, Spain. Ed. Elvira Sánchez Espiosa and Miguel Angel Garcimartin Molina, Universidad Politecnica de Madrid, Spain.

Perkins, P (1978). Measurements of slip between the shoe and ground during walking. In: Walkway Surfaces Measurements of Slip Resistance, vol. 649, ASTM Special Technical Publication, 71-87.

Phillips, C J C, Morris, I D (2001). The locomotion of dairy cows on floor surfaces with different frictional properties. Journal of Dairy Science. 84(3), 623-628.

Phillips, C J C, Morris, ID (2000). The locomotion of dairy cows on concrete floors that are dry, wet, or covered with a slurry of excreta. Journal of Dairy Science, 83, 1767-1772.

Powers, C M, Burnfield,J M, Lim, P, Brault, J M, Flynn, J E (2002). Utilizing coefficient of friction during walking: static estimates exceed measured values. Journal of Forensic Science, 47, 1303-1308.

Redfern, M S, Cham, R, Gielo-Perczak, K, Grönqvist, R, Hirvonen, M, Lanshammar, H, Marpet, M, Yi-Chung Pai, C, Powers, C (2001). Biomechanics of slips. Ergonomics, 44(13), 1138-1166.

Redfern, M S, DiPasquale, J (1997). Biomechanics of descending ramps. Gait and Posture, 1997(6(2)), 119-125.

Richter, T (2002). Skid proofing of concrete stable floors. Fourth International Symposium on Concrete for a Sustainable Agriculture - Agro-, Aqua- and Community Applications (ed. N. De Belie, Sonck, B.) Gent, Belgium, 61-68.

Roush, J K, McLaughlin, R M (1994). Effects of subject stance time and velocity on ground reaction forces in clinically normal Greyhounds at walk. American Journal of Veterinary Research, 55, 1672-1676.

Strandberg, L, Lanshammar, H (1981). The dynamics of slipping accidents. Journal of Occupational Accident, 1981(3), 153-162.

Tano, C A, Cockshutt, J R, Dobson, H, Miller, C W, Holmberg, D L, Taves, C L (1998). Force plate analysis of dogs with bilateral hip dysplasia treated with a unilateral triple pelvic osteotomy: a long-term review of cases. Veterinary and Compareative Orthopaedics and Traumatology, 11(2), 85-93.

Telezhenko, E, Bergsten, C (2005). Influence of floor type on the locomotion of dairy cows. Applied Animal Behaviour Science, 93, 183-197. 
Thorup, V, Tøgersen, F Aa, Jørgensen, B, Jensen, B R (2007). Biomechanical gait analysis of pigs walking on solid concrete floor. Animal, (1), 708-715.

van der Tol, P P J, Metz, J H M, Noordhuizen-Stassen, E N, Back, W, Braam, C R, Weijs, W A (2005). Frictional forces required for unrestrained locomotion in dairy cattle. Journal of Dairy Science, 88, 615-624.

Webb, N G (1984). Compressive Stresses on, and the Strength of, the Inner and Outer Digits of Pig's Feet, and the Implications for Injury and Floor Design. Journal of Agricultural Engineering Research, 30, 71-80.

Webb, N G, Clark, M (1981a). Livestock foot floor interactions measured by force and pressure plate. Farm Buildings Progress, 66, 23-36.

Webb, N G, Clark, M (1981b). Livestock limb floor biomechanics - Modelling, design and evaluation of livestock buildings. CIGR, Section II Seminar, 29-31 August, Scottish Farm Buildings Investigation Unit, Bucksburn, Aberdeen, 335-342.

Webb, N G, Nilsson, C (1983). Flooring and injury-an overview. In Farm Animal Housing and Welfare (ed: Baxter, S H, Baxter, M R, MacCormack, J A D). Martinus Nijhoff, Boston, USA. 226-259.

Whittle, M W (1999). Generation sand attenuation of transient impulsiveforces beneath the foot: a review. Gait and Posture, 10, 264-275.

von Wachenfelt, H, Pinzke, S, Nilsson, C, Olsson, O, Ehlorsson, C-J (2008). Gait analysis of unprovoked pig gait on clean and fouled concrete surfaces. Biosystems Engineering, 101, 376-382. 